\title{
Aus dem Zentralvorstand
}

\section{An seiner April-Sitzung hat der Zentralvorstand der FMH ...}

.. beschlossen, der Ärztekammer - im Rahmen der ordentlichen Neuwahl für die Treuhandstelle - das Büro Von Graffenried AG Treuhand (Bern) vorzuschlagen;

... entschieden, der Delegiertenversammlung den Entscheid zu überlassen, ob eine Motion «gegen die Entsolidarisierung in der Krankenversicherung durch sogenannte Billigkassen» von der FMH unterstützt werden soll;

... beschlossen, der Delegiertenversammlung die Stellungnahme der FMH zur Eidg. Volksinitiative «Für den Schutz vor Waffengewalt» vorzulegen;

... den Stand der Dinge im Projekt HPC (Health Professional Card) zur Kenntnis genommen. Bis zur Juli-Sitzung des ZV werden die Offerten vorliegen. Dem ZV wird anschliessend ein Vorschlag unterbreitet, mit welcher Firma das Projekt realisiert werden könnte;

... den Reglemententwurf der Geschäftsprüfungskommission zur Kenntnis genommen;

... beschlossen, eine Stellungnahme der FMH zum Entwurf der Verordnung 5 zum Arbeitsgesetz (ArGV5) auszuarbeiten. Darin geht es um den Schutz jugendlicher Arbeitnehmer vor gefährlichen Stoffen;
... folgende Nominierungen für den Verwaltungsrat der FMH Services gutgeheissen: Sven Bradke (Unternehmer), Max Giger (ZV-Delegierter), Thomas Paly (VEDAG-Delegierter), Vincenzo Liguori (OMTC-Delegierter) und Donatella Campus Souche (SMSR-Delegierte);

... entschieden, statistische Daten über die stationär tätigen Ärztinnen und Ärzte in der Schweiz an das Obsan (Schweizerisches Gesundheitsobservatorium) auszuhändigen;

... den Bericht über die Vereinbarung Radiologie RE III zur Kenntnis genommen;

... der MTK (Medizinaltarifkommission UVG) bewilligt, die Dignitätsdatenbank im bereits genehmigten Rahmen zu benutzen;

... beschlossen, den OMTC (Ordine dei Medici del Cantone Ticino) für die Nachfolge von Dr. Yvette Barbier im «Paritätischen Gremium Vertrauensarztvertrag» anzufragen;

... entschieden, dem Patronatskomitee des Pilotprojektes «Fassis» beizutreten. Im Projekt geht es um die Wiedereingliederung von Behinderten, speziell auch von psychisch Behinderten. 